\title{
The Przewalsky Horse, by Sándor Bökönyi, translated by Lili Halápy.
} Souvenir Press, $£ 2.75$

This popular Hungarian account of the rare Equus przewalskii, with good illustrations and many important and interesting facts, covers a wide ground in small compass: probable - perhaps better said possible - evolution and relation to domestic and other wild horses; history, description, and changes in captivity, with a glance at the future.

By comparison with the late Dr Erna Mohr's Asiatic Wild Horse (Allen 1959, reprinted in English four years ago) this one is able to consider most of the recent work; on the other hand the writing, translation, editing and, worse still, the decision among competing conjectures are slipshod. In the sense that the data are more complete, the later book is in general more reliable; in the sense that detail or expression are often confused or contradictory it is not reliable at all.

For example, the transliterations are eccentric and variable - the same Cyrillic letters are rendered in several ways. The name 'Przewalski' is treated as if it were Russian, whereas of course the explorer was a Pole, serving in the Russian army, so that the Latinised spelling of his name in the horse's specific name is correct. Sometimes a totally dubious conjecture is baldly reported as unchallenged fact: 'The wolf and the bear are the main natural enemies of the wild horse'; no instance of such an attack is either known to me or cited by the author. The natural enemies are cold and frost.

The text discredits, and for the right reasons, the earlier reports of two separate races, a dark one in the mountains and a light one in the plains, but this error has already been noted as a fact on a previous page. Vexed questions, such as proper nomenclature, are too easily disposed of, tall stories, like the carcase frozen in the Siberian tundra, too credulously reproduced. Perhaps a slightly misplaced chauvinism accounts for the fact that the sighting and photo by the Hungarian zoologist Dr Kaszab are reported (and republished) as though these had never been questioned or debated anywhere, let alone appeared originally in this very journal.

For the layman or very keen youngster, less insistent on accuracy of detail, more likely to respond to a full, and generally fair, easily readable account, this may be welcomed as the best book available. But the zoologist will be wise to give it shelfroom only in the safer company of Mohr and the two 'Equus' symposia.

IVOR MONTAGU

The Dictionary of Birds in Colour, by Bruce Campbell. Michael Joseph, $£ 6.00$ The Mitchell Beazley World Atlas of Birds. Mitchell Beazley, $£ 10.95$

These are two handsome and massive books on birds of the world, contrasted in their method of illustration and in their approach. Either could become a treasured possession. In Dr Campbell's the illustrations are from colour photographs. These average about five plates to the large page and are arranged in systematic order as a single compact section. They are mostly very successful in presenting the species in natural posture, colours and setting. There are 1008 plates, so that scarcely an eighth of the known species are figured; but the selection seems to be reasonably representative. The following section comprises a series of paragraphs corresponding with convenient cross-references under English names. There is also a relatively short Introduction dealing generally with faunal regions, evolution, anatomy and classification. The whole is a scholarly production.

The Mitchell Beazley atlas appears to be the product of a publisher's staff team, aided by a galaxy of expert editors and contributors whose individual parts are not made clear. Apart from photographs of habitats, the illustrations are the work of artists; some are beautiful, but others are less satisfactory in their rendering of natural form and colour. They are often usefully combined with maps and other 